\title{
MUSEOLOGIA E CIÊNCIA DA INFORMAÇÃO: DIÁLOGOS POSSÍVEIS
}

\author{
Carlos Alberto Ávila Araújo' \\ Universidade Federal de Minas Gerais
}

\section{RESUMO:}

Apresentam-se alguns exemplos de fatos institucionais, profissionais e formativos que anunciam oportunidades de cooperação entre a Museologia e a Ciência da Informação. A seguir, analisa-se a evolução teórica da Museologia: de um modelo centrado nas técnicas e nas instituições para as perspectivas contemporâneas em torno do museal e da complexidade. Paralelamente, analise-se a evolução teórica da Ciência da Informação, a partir de suas diferentes subáreas, em torno de três grandes conceitos de informação: o físico, o cognitivo e o pragmático/social. Conclui-se que o cenário epistemológico é amplamente favorável ao diálogo entre as duas áreas, em sintonia com as iniciativas práticas já em curso, no Brasil e no contexto internacional.

\section{PALAVRAS-CHAVES:}

Museologia. Ciência da Informação. Epistemologia.

\begin{abstract}
:
In this article we present some examples of institutional, professional and teaching facts that demonstrate the cooperation between Museology and Information Science. Next, we analyze the theoretical evolution of Museology, from a model based on techniques and institutions for contemporary perspectives around the museological and complexity. In parallel, we analyze the theoretical evolution of Information Science, from their different subareas, around three major concepts of information: the physical, cognitive and pragmatic/social. We conclude that the epistemological framework is largely favorable to dialogue between the two areas, according with the practical initiatives already underway in Brazil and in the international context.
\end{abstract}

\section{KEY-WORDS:}

Museology. Information Science.

Epistemology.

I Professor do curso de Museologia da Escola de Ciência da Informação da Universidade Federal de Minas Gerais (ECI/UFMG). Doutor em Ciência da Informação pela UFMG e pós-doutor pela Faculdade de Letras da Universidade do Porto. E-mail: casalavila@yahoo.com.br. 


\section{Introdução}

Diversas iniciativas profissionais e institucionais recentes, no Brasil e no exterior, têm sinalizado a presença de interlocuções entre as áreas da Museologia e aquelas dedicadas ao estudo da informação - a Ciência da Informação, a Arquivologia e a Biblioteconomia.Ao mesmo tempo, o contexto formativo brasileiro contemporâneo também tem apresentado sinais claros de parceria entre essas áreas.

Esse cenário tem estimulado a produção de reflexões epistemológicas voltadas para o estabelecimento de pontos comuns, interfaces e possibilidades de cooperação entre essas áreas. Nesse sentido, a produção científica em Museologia, que sempre se deu em forte diálogo com diversos campos (como a História, as Artes, a Antropologia, entre outros), tem tido atualmente também a Ciência da Informação como interlocutora na formação de teorias, conceitos e métodos. Ao mesmo tempo, o campo da Ciência da Informação, constituído historicamente por meio de parcerias entre a Biblioteconomia, a Computação, a Comunicação e as Ciências Cognitivas, vem gradualmente se voltando, primeiro para a Arquivologia e, mais recentemente, para a Museologia, incorporando temáticas e problemas voltados para a memória, o patrimônio e a cultura.

Mas essa aproximação não é apenas reflexo do cenário profissional, institucional e formativo contemporâneo. Também é resultado da própria evolução teórica e conceitual destes campos. Na Museologia, o modelo custodial e patrimonialista consolidado no início do século $X X$ foi sendo cada vez mais ampliado por meio de perspectivas funcionalistas, críticas, construtivistas e aquelas voltadas para o estudo das representações. $O$ resultado dessa evolução, como se pretende demonstrar neste texto, define para o campo não uma perspectiva de "ciência do museu", mas sim do museal ou dos processos de musealização - o que permite pôr em destaque a importância do conceito de "informação", ou de uma dimensão informacional, como elemento-chave desse processo.

Ao mesmo tempo, a Ciência da Informação nasceu, na década de 1960 , a partir de uma perspectiva fisicista de estudo da informação. Nas décadas seguintes, contudo, por meio da evolução teórica em diferentes subáreas (comunicação científica, gestão da informação, economia política da informação, representação da informação, estudos de usuários e estudos métricos), consolidou-se um modelo cognitivista de estudos e, mais recentemente, um modelo pragmático, que prevê o estudo da informação articulada às ações humanas e aos contextos socioculturais. E é justamente esse modelo, como também se pretende demonstrar neste texto, que possibilita o estudo dos fenômenos museais a partir da dimensão informacional destes.

Assim, neste texto, busca-se explorar especificamente a evolução teórica e conceitual da Museologia e da Ciência da Informação, para se evidenciar como as perspectivas de estudo contemporâneas, nas duas áreas, sugerem um interessante campo de problematizações comuns e questões transversais.

\section{Alguns fatos recentes}

Em fevereiro de 2013 foi realizada a primeira reunião de trabalho prevista no acordo de cooperação assinado entre o Arquivo Nacional, a Fundação Biblioteca Nacional e o Instituto Brasileiro de Museus (lbram) em dezembro de $201 \mathrm{I}$. Tal acordo é uma iniciativa para a preservação e democratização do conteúdo informacional de 105 mil instituições brasileiras que estão sob o "guarda-chuva" destas três instituições. A existência desse acordo é um claro sinal de que os desafios colocados pela preservação e pelo acesso aos acervos, nos tempos 
atuais, transcendem as fronteiras da atuação isolada de arquivistas, bibliotecários e museólogos, convocando-os a necessariamente atuar em parceria - e também em conjunto com profissionais de outras áreas, como da informação, da gestão, da computação, entre outras.

Em março de 2013, a Biblioteca Brasiliana da Universidade de São Paulo sediou o "Seminário internacional sobre sistemas de informação e acervos digitais de cultura". Promovido pela Secretaria de Políticas Culturais do Ministério da Cultura, tal seminário teve por objetivo apresentar os resultados de uma parceria feita entre o Ministério da Cultura brasileiro e a União Europeia para realização de missões técnicas a instituições que trabalham com sistemas de informações de acervos digitais de arquivos, bibliotecas e museus. Tal parceria se insere no Projeto de cooperação internacional "Diálogos Setoriais UE-Brasil" e tem um duplo objetivo: possibilitar a implementação de sistemas públicos de informação; e disponibilizar o acesso a acervos digitais de bibliotecas, arquivos e museus. É mais uma ação que evidencia, no cenário atual, uma tendência de aproximação e colaboração entre essas áreas.

Tais eventos, brasileiros, estão em sintonia com um movimento que é mundial. Em abril de 2013, promoveu-se uma nova convocatória para o programa Memória do Mundo, por parte do Comitê Regional para a América Latina e Caribe da Organização das Nações Unidas para a Educação, a Ciência e a Cultura (Unesco). O objetivo do programa é integrar acervos documentais de arquivos, bibliotecas e museus, a partir de ações de salvaguarda e promoção de acesso por meio de políticas de informação e digitalização. Ainda na América Latina, esse tipo de tendência provocou, entre outras ações, o surgimento do Encuentro Latinoamericano de Bibliotecarios,Archivistas y Museólogos (EBAM), que ocorreu pela primeira vez em 2009, tendo sua última edição acontecido na Argentina, em 2012 - com previsão de que o próximo aconteça no Brasil. A Argentina, particularmente, mostra-se preocupada com essa questão, tendo sediado, em 2010, o I Congreso Nacional de Archivos, Bibliotecas y Museos.

$\mathrm{Na}$ Europa, muitos são os exemplos nesse sentido, entre os quais se destaca a criação da Europeana, um amplo sistema digital informacional que constitui ao mesmo tempo um arquivo, uma biblioteca e um museu de acervos da cultura europeia. Na França, diversos programas de política cultural promovem ações integradas entre arquivos, bibliotecas, museus e centros de documentação - o Centre Pompidou, em Paris, é um exemplo de uma eficaz integração de arquivo, biblioteca, midiateca, teatro, centro de inclusão digital e museu, todos funcionando num único edifício. $\mathrm{Na}$ Inglaterra, o relatório Sustaining our digital future: institutional strategies for digital content, publicado em 2012 e organizado por Nancy Maron, Jason Yun e Sarah Pickle, aponta uma série de questões transversais a arquivos, bibliotecas e museus relacionados aos acervos digitais (e em processo de digitalização) destas instituições; enquanto o Projeto Discovery vem desde maio de 201 I trabalhando para a criação de uma "ecologia de metadados", para garantir maior acesso às coleções de arquivos, bibliotecas e museus, por meio de arranjos open linked data para disponibilização integrada de catálogos de arquivos, bibliotecas e museus.

No Brasil, a sensibilidade para essa questão concretizou-se em 2002, quando ocorreu o I Integrar - Congresso Internacional de Arquivos, Bibliotecas, Centros de Documentação e Museus, em São Paulo. A ideia original era a de que o evento deveria acontecer a cada quatro anos. De fato, em 2006 aconteceu a segunda edição, mas a terceira, que deveria ser realizada em 2010 , ainda não se efetivou. Contudo, em 20I I, Salvador sediou o "Encontro de Arquivos, 
Bibliotecas e Museus à luz da era pós-custodial- um diálogo Brasil-Portugal" e, em 2012, a mesa redonda "Aproximações entre Arquivologia, Biblioteconomia e Museologia: ideias e propostas" teve lugar no Enecin, o Encontro Nacional de Ensino em Ciência da Informação.

Esse amplo campo de atuação encontra ressonância na conformação institucional destas áreas. No Brasil, existem hoje 16 cursos de graduação em Arquivologia, 37 cursos de Biblioteconomia e 14 de Museologia. Tanto na Universidade de Brasília, quanto na Universidade Federal de Minas Gerais e na Universidade Federal do Rio Grande do Sul, estes três cursos estão sediados em escolas/departamentos de Ciência da Informação.Além da convivência institucional, a realidade nestas universidades tem sido a de realização de atividades comuns (disciplinas, pesquisas, ações de extensão) aos três cursos e deles com os programas de pós-graduação em Ciência da Informação. Esse conjunto de atividades tanto é sintoma da realidade institucional apontada acima, no Brasil e no exterior, como também funciona como elemento fertilizador para inovações teóricas e formativas em cada uma das áreas envolvidas.

O que se destaca, nesse amplo quadro institucional, é a existência de vários espaços de interlocução e cooperação entre as áreas. Contudo, é no plano epistemológico que se verificam as condições mais frutíferas para a promoção de parcerias e diálogos - como se pretende evidenciar a seguir.

\section{A evolução teórica da Museologia}

De acordo com Duarte (2007, p. 27-28),“a conscientização de um sentido museológico estará inerente ao próprio ser humano na medida em que, desde tempos ancestrais, o homem pratica uma recolha de materiais diversos pelas mais diversas razões". Assim, a ideia de musealidade, antes até do que a de museu, mistura-se à ação humana de intervir na realidade (natural e humana), reconhecendo nela objetos e elementos a serem guardados, colecionados, exibidos, atribuindo significados a estes objetos.

O termo "museu", originário do contexto grego, ressurgiu com o Renascimento, para descrever as coleções de arte como a de Lorenzo de Médici, em Florença (WOODHEAD; STANSFIELD, 1994), e foi com ele, a partir do século XV, que apareceram os primeiros traços efetivos daquilo que se poderia chamar de um conhecimento teórico específico em Museologia, com a publicação dos primeiros tratados relativos aos museus, como os de Quiccheberg, Comenius e Camilo (MAIRESSE; DESVALLÉS, 2005). Renasceu, nessa época, o interesse pela produção humana, pelas obras artísticas, filosóficas e científicas - tanto as da Antiguidade Greco-Romana como aquelas que se desenvolviam no próprio momento. Salientou-se assim o interesse pelo culto das obras, pela sua guarda, sua preservação.

Proliferaram, entre os séculos $\mathrm{XV}$ e XVII, tratados e manuais voltados para as regras de procedimentos nas instituições responsáveis pela guarda das obras, para as regras de preservação e conservação física dos materiais, para as estratégias de descrição formal das peças e documentos, incluindo aspectos sobre sua legitimidade, procedência e características.

A produção simbólica humana, compreendida como um "tesouro" que precisaria ser devidamente preservado, tornou-se objeto de uma visão patrimonialista (o conjunto da produção intelectual e estética humana, a ser guardado e repassado para as gerações futuras). Contudo, o foco do interesse fixou-se no conteúdo dos acervos, constituindo os museus apenas em instituições a serviço dos campos de estudo da Literatura, das Artes, da História e das ciências. Não 
se construíram, neste momento, conhecimentos propriamente museológicos (para além de algumas regras operativas muito próximas do senso comum), mas apenas conhecimentos artísticos, literários, filosóficos ou históricos sobre os conteúdos guardados nestas instituições.

O passo seguinte na evolução da área se deu com a Revolução Francesa e as demais revoluções burguesas na Europa, que marcam a transição do Antigo Regime para a Modernidade. Operou-se uma profunda transformação em todas as dimensões da vida humana (na política, na economia, no direito) e, dessa forma, também os museus foram drasticamente transformados. Surge o conceito moderno de "Museu Nacional", que tem no caráter público (no sentido de "nacional", relativo ao coletivo dos nascentes Estados modernos) sua marca distintiva, e no Musée du Louvre sua instituição paradigmática (POULOT, 2002). São formadas as grandes coleções, operam-se amplos processos de aquisição e acumulação de acervos - o que reforçou a natureza custodial destas instituições. A necessidade de se ter pessoal qualificado para os nascentes museus modernos levou à formação dos primeiros cursos profissionalizantes, voltados essencialmente para regras de administração das rotinas dos museus e, seguindo a tradição anterior, para conhecimentos gerais em Artes e Humanidades (ou seja, os assuntos dos acervos guardados).

Por fim, com a consolidação da ciência moderna como forma legítima de produção de conhecimento e de intervenção na natureza e na sociedade, também o campo das humanidades se viu convocado a constituir-se como ciência. Surgiram então, ao longo de todo o século XIX, diversos manuais, como os de Rathgeber, Graesse e Reinach, que buscaram estabelecer o projeto de constituição científica do campo dedicado aos museus, mas ainda na vertente de uma "Museografia", isto é, de um trabalho técnico de descrição nos museus, na linha inaugurada por Neickel em 1727 (MAIRESSE; DESVALLÉS, 2005).

O modelo de ciência então dominante, oriundo das ciências naturais, voltado para a busca de regularidades e desenvolvimento de instrumentos técnicos para intervenção na natureza, se expandiu para as ciências sociais e humanas através do Positivismo. Esse modelo inspirou as pioneiras conformações científicas da área, que privilegiou os procedimentos técnicos de intervenção: as estratégias de inventariação, descrição, ordenação e exposição dos acervos museológicos. É nesse sentido que a primeira conformação científica do campo aproxima-se mais da noção de museografia: um conjunto de práticas, de técnicas, a serem aplicadas junto aos acervos guardados nas instituições museais.

Foi por meio desse movimento de consolidação positivista que se promoveu, contudo, a "libertação" da Museologia das outras disciplinas das quais ela era apenas um campo auxiliar (as Artes e a História, sobretudo). Houve uma relativa autonomização, abrindo caminho para a construção de um campo científico específico dedicado aos museus. Esse movimento foi reforçado nos anos seguintes com a criação das primeiras associações profissionais (a primeira foi a Museum Association criada em Londres, em (889) e a atuação dos movimentos associativos - que levaram à criação do Office International des Museés (OIM), em Paris, em 1926 (MAIRESSE; DESVALLÉS, 2005).

Mais do que oposições, os três movimentos acima destacados se somam. A perspectiva custodial renascentista voltou-se para os "tesouros" que deveriam ser preservados, ressaltando a importância da produção simbólica humana. A entrada na Modernidade enfatizou as especificidades da instituição museu, que deveria ter estruturas organizadas e rotinas estabelecidas para o exercício da custódia. E a fundamentação positivista deu mais ênfase às técnicas museo- 
gráficas a serem utilizadas para o correto tratamento e exposição do material custodiado. Constituíram-se assim, no século XIX, os elementos que marcaram a consolidação de um modelo que representa, ao mesmo tempo, a ideia de uma "ciência do museu" (voltada para o funcionamento e as rotinas desta instituição); de uma área dedicada ao "patrimônio" (à preservação de seu acervo e sua salvaguarda para as gerações futuras); e de uma "museografia" (das técnicas empregadas para o tratamento do acervo acondicionado na instituição museu).

Contudo, nas décadas seguintes, os estudos museológicos desenvolveram-se em diferentes frentes que foram apontando para uma progressiva superação deste primeiro modelo. Tais pesquisas são apresentadas a seguir, organizadas em quatro eixos: os estudos funcionalistas, a perspectiva crítica, os estudos de público e as pesquisas sobre representação.

Ainda nos finais do século XIX, começam a surgir ensaios, manifestos e iniciativas que evocam mudanças no modo de se conceberem os museus. Adjetivos como "vivo", "dinâmico", "atuante" e "ativo" começaram a ser usados para apontar a direção de uma necessária mudança a ser operada nestas instituições de modo a se combater sua inércia e seu fechamento sobre si mesmas, seu isolamento do conjunto geral da sociedade. $O$ ideal iluminista da universalidade, isto é, do acesso a todos os cidadãos, é um dos motes dessa abordagem. De outro lado, o discurso da eficácia, o imperativo do retorno, para a sociedade, dos investimentos feitos, também convoca a que se pense e problematize as funções dos museus.

No ambiente anglo-saxão, a área da Museum Education buscou desenvolver uma museologia "verbal", voltada para a ação, em oposição à tradição voltada para a posse e a descrição dos objetos (GÓMEZ MARTíNEZ, 2006). Zeller (1989) aponta que tal tendência se voltava para a eficácia dos museus, para uma efetiva difusão de certos valores junto à população, e para oferecer à sociedade um "retorno" dos investimentos feitos. Autores como Flower, Goode, Dana, Rea e Coleman marcavam a especificidade dos novos museus como instituições que teriam como valor não a contemplação mas o uso, e que não esperariam pelos visitantes, mas iriam "buscá-los", atraindo-os para os museus por meio da eliminação de barreiras e da busca por acessibilidade.

Essa perspectiva manifestou-se em diversos outros contextos, como na França, sob inspiração do "museu imaginário” de André Malraux, e no Canadá, a partir do conceito de "comunicação" presente nos trabalhos de Cameron (1968).A partir da década de 1980, com as tecnologias digitais, houve uma revitalização da corrente funcionalista, com as possibilidades de acesso remoto, interatividade e design de exposições, desenvolvida por autores como Merriman, Pearce, Arnold, Hooper-Greenhill e Vergo.

Logo na virada do século $X I X$ para o século $X X$, o impacto do pensamento crítico sobre o positivismo, a sociedade e o ser humano começou a se manifestar no espaço reflexivo sobre os museus. Também tendo como centro de preocupação as relações entre essas instituições e a sociedade, desenhou-se uma perspectiva calcada sobretudo na denúncia de processos de dominação, de ações ideológicas ocultas por detrás de práticas tidas como pretensamente neutras, no questionamento sobre as reais necessidades a serem atendidas e sobre os enquadramentos culturais promovidos.

As manifestações pioneiras de pensamento crítico na Museologia se encontram na obra de artistas e ensaístas como Zola, Valéry e Marinetti (BOLAÑOS, 2002), que viam o museu como "mausoléu", instituição que degradava a arte, instrumento de poder de alguns povos sobre outros. Na década de 1960, uma 
nova onda de críticas provocou o aparecimento de formas de "antimuseu" (BOLAÑOS, 2002). Porém, foi na aproximação com a sociologia da cultura que se deram as manifestações mais consolidadas da perspectiva crítica, com Bourdieu (2007) inspirando uma geração de pesquisadores para ver como diferentes grupos sociais tinham relações distintas com a cultura (e inclusive com os museus). Outros estudos buscam correlacionar o papel que os museus tiveram (e ainda têm) na construção ideológica da idéia de nação, a partir do trabalho pioneiro de Anderson (2008). Há ainda uma área recente, a "Museologia Crítica", voltada para a crítica das estratégias museológicas intervenientes nos patrimônios naturais e humanos (SANTACANA MESTRE; HERNÁNDEZ CARDONA, 2006).

Nascidos como uma extensão da perspectiva funcionalista que buscava obter indicadores de satisfação, os estudos de público eram primeiramente ferramentas de diagnóstico para o planejamento e a otimização dos serviços. Aos poucos, foram se convertendo em subárea com relativa autonomia. Neste processo, se afirmaram a partir da crítica tanto aos estudos funcionalistas como aos críticos, na medida em que ambos tendiam a ver apenas a ação dos museus sobre os indivíduos, estes tomados apenas como seres passivos, meros receptáculos de informação. Foi no resgate ao papel de sujeitos ativos e no estudo de suas apropriações, suas diferentes necessidades e usos que se construiu toda uma tradição de estudos.

Os primeiros estudos empíricos de visitantes foram realizados no começo do século $X X$ por Galton, que seguia os visitantes pelos corredores dos museus, e por Gilman, que estudou a fadiga e os problemas de ordem física na concepção de exposições (HOOPER-GREENHILL, 1998). Na década de 1940, proliferaram estudos sobre os impactos nas exposições junto aos visitantes, realizados por autores como Cummings, Derryberry e Melton. Outros estudos, conduzidos por autores como Rea e Powell na mesma época, tiveram como objetivo traçar perfis sociodemográficos dos visitantes e mapear seus hábitos culturais (PÉREZ SANTOS, 2000). Na década de 1960, Shettel e Screven inauguraram uma nova perspectiva com as medidas de aprendizagem. Nas décadas seguintes, desenvolveram-se abordagens de base cognitivista (Eason, Friedman, Borun) e de natureza construtivista - como o modelo tridimensional de Loomis, a teoria dos filtros de McManus, o modelo sociocognitivo de Uzzell, a abordagem comunicacional de Hooper-Greenhill e o modelo contextual de Falk e Dierking.

O quarto eixo relaciona-se com os estudos sobre representação. Desde sua origem como instituições modernas, os museus viram-se às voltas com tarefas relacionadas à representação de seus acervos. Inventariar, repertoriar, catalogar, classificar, nomear, descrever, indexar, organizar, tratar são alguns dos termos que desde então vêm sendo utilizados para tratar de um campo de intervenções práticas que, tomados a um nível tecnicista, chegaram a se constituir como parte essencial ou nuclear da nascente Museologia.

O espírito nacionalista e historiográfico dos primeiros museus modernos foi decisivo para a configuração de critérios de ordenamento, descrição, classificação e exposição dos acervos (MENDES, 2009).A subárea de Documentação Museológica surgiu no início do século $X X$, a partir do trabalho de autores comoWittlin, Taylor e Schnapper (MARÍNTORRES, 2002). Nas décadas de 1920 e 1930 houve grandes debates sobre os critérios de classificação adotados nos museus, mas a temática só se converteu em campo de investigação décadas depois. Entre as várias abordagens desenvolvidas, encontram-se aquelas que buscaram problematizar aspectos classificatórios dos museus, como a questão da representação dos gêneros, dos diferentes povos do mundo, das diferentes 
culturas humanas, numa linha marcada pelos cultural studies (PEARCE, 1994). Os aspectos envolvidos no trabalho de ordenamento também foram estudados por Bennett (2004) numa perspectiva foucaultiana.

Os avanços mais recentes em Museologia têm buscado agregar as contribuições das várias teorias e práticas desenvolvidas ao longo do século XX (apresentadas acima agrupadas em quatro eixos) de forma a superar o caráter limitado do quadro teórico do modelo custodial/tecnicista. Novos tipos de instituições, serviços e mesmo ações executadas no âmbito extra-institucional conferiram maior dinamismo ao campo teórico e à prática. Para superar os modelos voltados apenas para a ação dos museus junto aos visitantes, ou apenas para os usos que os visitantes fazem das exposições, surgiram também modelos voltados para a interação e a mediação, contemplando as ações reciprocamente referenciadas destes atores. Modelos sistêmicos também surgiram na tentativa de integrar ações, acervos ou serviços antes contemplados isoladamente.A própria ideia de acervo, ou item de coleção, foi problematizada, na esteira de questionamentos sobre o objeto da Museologia e sobre o imaterial como objeto museológico. Desenvolveram-se, ainda, as tecnologias digitais, com um impacto profundo sobre os museus, reconfigurando tanto o fazer quanto a teorização sobre o museu.

Entre os diversos desenvolvimentos teóricos e práticos no campo da Museologia que ocorreram nas últimas décadas, destaca-se a questão dos ecomuseus e da Nova Museologia. Contudo, é preciso algum cuidado no exame destes termos, pois são usados para designar diferentes questões e, algumas vezes, ainda confundidos um com o outro ou tomados como sinônimos.

Davis (1999) explica que o conceito de "ecomuseu" surgiu no começo do século $X X$, sob o impacto das ideias ambientalistas, com a criação dos chamados "museus ao ar livre", que, numa perspectiva ampliada de museu, incorporavam sítios geológicos ou naturais ao seu "acervo". Um outro sentido para o termo foi dado no âmbito do movimento da Nova Museologia. Surgida a partir das ideias de Georges Henri Rivière, Hugues de Varine-Bohan e Germain Bazin, ligados à Ecole du Louvre, mas atuantes no seio do ICOM, a Nova Museologia propôs-se a repensar o significado da própria instituição museu. Nessa visão, os museus deveriam envolver as comunidades locais no processo de tratar e cuidar de seu patrimônio. Como coloca Davis (1999), o termo “território" é então utilizado para definir tanto os limites geográficos como também as conotações dos sujeitos e comunidades que vivem no espaço, as apropriações que fazem dele. Com isso, ressurgiu o conceito de ecomuseu, mas tomado num sentido que incorpora também as identidades culturais e a ideia de comunidade. Van Mensch (1995) caracterizou esse movimento como a "segunda revolução" no campo da Museologia. Mudou o sentido de museu, de lugar de entrega de um conhecimento a uma comunidade (transmissão), para lugar construído pela própria comunidade (veículo de expressão de uma identidade).

A primeira expressão pública e internacional deste movimento se deu em 1972, na Mesa Redonda de Santiago do Chile, organizada pelo ICOM, que buscou debater a função social do museu e o caráter global das suas intervenções. Daí surgiu a ideia do museu integral, que deveria proporcionar à comunidade uma visão de conjunto de seu meio material e cultural. Do ponto de vista teórico, tal noção busca propor que a relação que o homem estabelece com o patrimônio cultural passe a ser estudada pela Museologia e que o museu seja entendido como instrumento e agente de transformação social - o que significa ir além das suas funções tradicionais de identificação, conservação e educação, em direção à inserção da sua ação nos meios humano e físico, integrando as po- 
pulações na sua ação. O movimento foi formalizado na Declaração de Quebec, em 1984, nascendo aí o Movimento Internacional para uma Nova Museologia (MINOM). Defendendo a participação comunitária no lugar do "monólogo" do técnico especialista, tratou de colocar no lugar do tradicional tripé edifício/ coleções/público da Museologia uma nova rede de conceitos composta por território, patrimônio e comunidade (ALONSO FERNÁNDEZ, 1999).

A Nova Museologia recebeu adesão de teóricos de várias partes do mundo, como Burcaw (EUA), Van Mensch (Europa Ocidental) e Stránský (Leste Europeu). Teve diversos desdobramentos práticos (vários ecomuseus espaIhados pelo mundo), teóricos (na direção de novas definições da instituição museu) e no âmbito da formação (influenciando os programas em estudos museológicos de centros como os de Brno, Leicester, Leiden, Newark, além da própria Ecole du Louvre).

Uma contribuição também mais específica, mas que teve efeitos na Museologia como um todo, foi a reflexão sobre a musealização, que "consiste na metamorfose de objectos que, não deixando de ter valor social e cultural, adquirem outro, mais especial, com a nova recontextualização" (MAGALHÃES, 2005, p. I2). Dessa forma, a musealização, mais do que mero processo técnico de adquirir, documentar e exibir um objeto, significa um "caminho que consiste em transformar objetos materiais e imateriais aparentemente vulgares em legados históricos ou testemunhos do desenvolvimento científico, técnico, artístico ou outro de uma determinada cultura" (MAGALHÃES, 2005, p. 12). Fernández de Paz e Agudo Torrico (1999) ressaltam que a discussão sobre a musealização traz uma problematização sobre quais bens ou objetos serão musealizados, isto é, que serão destacados como de especial significado dentro de um contexto cultural - e ainda, uma vez realizado esse processo, de que forma eles serão interpretados na realidade museal. Conforme os autores, essa questão começou a ser problematizada no âmbito da Comissão Franceschini, formada em 1966 para discutir a questão dos "bens culturais" a serem patrimonializados, tendo como desdobramento a Convenção da Unesco em Paris, em 1972, sobre a proteção ao Patrimônio Mundial Cultural e Natural.

Nesta nova concepção de patrimônio, de uma só vez passou-se a considerar nas definições do interesse patrimonial a conhecer e proteger dois terços dos componentes do entorno cultural do ser humano: o natural (conceito modificado mais tarde para 'paisagens culturais' para reconhecer mais acertadamente a relação simbiótica que se dá entre ser humano e seu entorno físico) e o etnológico (no qual se inserem as atividades e conquistas - materiais e imateriais - que formam parte da bagagem mais cotidiana que contribui para dotar de uma identidade diferenciada cada coletivo). Com isso, buscou-se pôr fim a uma dinâmica surgida com a expansão colonial européia: a desvinculação entre objetos e sujeitos sociais, processo pelo qual os bens culturais (objetos materiais, representações simbólicas, rituais) teriam valor em si mesmos, desligados de quem os seguem criando e reproduzindo.

Uma questão especial discutida nos estudos contemporâneos em Museologia diz respeito à questão do patrimônio imaterial. Os primórdios dessa questão se encontram numa convenção da Organização das Nações Unidas para a Educação (Unesco) realizada em Haia, em 1954, e uma versão formalizada na Convenção de Belgrado em 1980. Para a Unesco, o patrimônio cultural imaterial abrange

[...] as tradições e expressões orais, incluindo a língua como vector do património cultural imaterial; as artes do espetáculo; as práticas sociais, rituais e acontecimentos festivos; os conhecimentos e práticas 
que dizem respeito à natureza e ao universo; os saberes fazer ligados ao artesanato (LEAL, 2009, p. 289).

Alargando seus horizontes dessa forma, a Museologia se desloca da ênfase nos objetos para a dimensão imaterial da ação humana e dos sentidos construídos.

Por fim, o fenômeno contemporâneo dos museus virtuais representa uma ampla dimensão com desdobramentos práticos e teóricos. Para Deloche (2002), a chegada da tecnologia digital à realidade dos museus representa muito mais do que apenas uma conjuntura nova à qual se adaptar, reformulando a própria concepção da instituição museal. Sem edifício ou coleções, marcos institucionais tradicionais, o museu precisa oferecer novos serviços, por meio de novas práticas e funções. Os usuários também se modificam em termos de ações e possibilidades. Assim, a adoção de tecnologias para o tratamento e o planejamento de exposições aproxima o museu do conceito de sistema de informação (HIGGINS; MAIN; LANG, 1996). Têm se desenvolvido ainda estudos numa área específica denominada Museum Informatics, que trata das interações sociotécnicas que ocorrem entre as pessoas, a informação e a tecnologia nos espaços museais (MARTY; JONES, 2008). Aliada à discussão do patrimônio imaterial, também tal dimensão relaciona-se ao que vem sendo denominado "patrimônio cultural digital" (ZORICH, 20I0).

O conjunto de teorias apresentadas neste tópico permite perceber como os modelos contemporâneos representam principalmente um grau maior de abstração na compreensão do fenômeno museal. Se o desenho das reflexões que vão do Renascimento ao século XIX ancora-se na extrema concretude dos objetos (a instituição museu, os acervos, as técnicas), as perspectivas desenvolvidas no século $X X$ foram importantes para deslocar e ampliar o eixo de preocupações (para as funções sociais dos museus, seu papel nos tensionamentos sociais, as apropriações dos sujeitos, os efeitos de sentido gerados por seus acervos e pelas técnicas aplicadas). É o aprofundamento desse processo que acaba por conduzir às perspectivas contemporâneas, mais atentas à complexidade dos fenômenos e à interrelação de seus elementos constituintes.

\section{A evolução da Ciência da Informação}

A origem da Ciência da Informação deve ser buscada no paradigma consolidado, no final do século XIX, nas ciências relacionadas com o documento (a Biblioteconomia, principalmente, mas também a Arquivologia e a Museologia), pois foi em diálogo com ele - mas buscando ser uma outra coisa - que surgiu o campo da Documentação, que anos depois propiciou o surgimento da Ciência da Informação.

A Documentação, campo de reflexão e atuação prática criado por Otlet e La Fontaine no início do século XX, voltou-se para a tentativa de se promover um inventário da totalidade dos registros do conhecimento humano - e não para o armazenamento ou a custódia destes registros, tal como vinha sendo realizado pelos arquivos, pelas bibliotecas e pelos museus. No âmbito desta ação, Otlet desenvolveu o conceito de "documento", alargando o campo de intervenção para além dos livros e documentos administrativos. Embora tratando de arquivos, bibliotecas (e também museus e demais entidades documentais) numa perspectiva integradora, a área acabou se desenvolvendo como uma atividade profissional distinta, paralela, atuando principalmente no campo da informação científica e tecnológica (DAY, 200I). 
Foi justamente neste espectro de atuação, do registro e fornecimento de informações para campos específicos de ciência e tecnologia, que começaram a atuar aqueles que primeiramente ficaram conhecidos como "cientistas da informação" (FEATHER; STURGES, 2003). Na esteira das tentativas de institucionalização das atividades destes profissionais deu-se a base para a criação da nascente "Ciência da Informação", que teve como marcos a International Conference on Scientific Information, realizada em Washington, em 1958, e a mudança, em 1966, do nome do American Documentation Institute (ADI) para American Society for Information Science (ASIS), tornando-se a primeira instituição científica específica da Ciência da Informação. A mudança de nome desta instituição inspirou outras, o que fez com que, na prática, a Ciência da Informação acabasse por ocupar o espaço institucional da Documentação e, por extensão, também o espaço de produção teórica e científica (SHERA; CLEVELAND, 1977).

Os fundamentos teóricos imediatamente adotados pelo campo foram a Teoria Matemática da Comunicação de Shannon e Weaver, a Cibernética de Wierner e as contribuições de Vannevar Bush. Juntos, tais contributos permitiram a elaboração de um conceito "científico" de informação e a agenda de pesquisa da área, expressa num artigo de Borko, publicado em 1968, que se tornou um clássico. Nessa visão, a Ciência da Informação desenhava-se basicamente como uma ciência da transferência da informação, isto é, dedicada ao estudo e desenvolvimento de processos e serviços para garantir com eficácia e eficiência o transporte do "conteúdo objetivo" dos documentos de um emissor a um receptor. Contudo, a Ciência da Informação superou, nos anos seguintes, esse modelo consolidado em sua origem na década de 1960, a partir do desenvolvimento de subáreas ou diferentes "programas de pesquisa".

A primeira destas áreas está na origem mesma da $\mathrm{Cl}$ : o estudo da informação científica e tecnológica (ICT). Os estudos iniciais estiveram voltados para a busca de caracterizações universais das diferentes fontes e recursos informacionais presentes na prática científica (tempo de produção de cada um deles, vantagens e desvantagens, completude, custos, etc).Ao longo dos anos, esses estudos se deslocaram para as práticas informacionais dos cientistas, identificando a importância da comunicação informal (com a descoberta dos "colégios invisíveis"), ampliando o foco de observação dos fenômenos. Mais recentemente, começaram a ser desenvolvidos estudos a partir do conceito de "rede", analisando as ações informacionais dos cientistas tomados como coletivo interrelacionado e não apenas no nível individual.

Uma segunda subárea se desenvolveu utilizando o mesmo instrumental da ICT, porém no ambiente organizacional. Surgiram aí os estudos em gestão da informação e do conhecimento, que também trouxeram uma série de inovações. Num primeiro momento voltaram-se para as diferentes fontes de informação (internas ou externas às organizações) e suas características e papel nos processos decisórios, naquilo que ficou conhecido como "gestão de recursos informacionais". Com o avanço das pesquisas, percebeu-se a importância de se estudar os conhecimentos que os membros das organizações detinham, porém ainda não existiam fisicamente. Iniciou-se uma distinção entre "conhecimento tácito" e "conhecimento explícito" (tomada da filosofia de Polanyi) que ajudou a esclarecer ainda mais as distinções entre documento e informação. No âmbito dessa subárea também foram estudados os processos por meio dos quais conhecimentos tácitos tornam-se explícitos e vice-versa. Em anos mais recentes, vêm sendo estudada a natureza coletiva desse processo, em torno dos estudos sobre "cultura organizacional" e os ambientes de produção e uso da informação. 
Uma terceira subárea também utilizou os mesmos pressupostos da área de ICT, porém voltados para o ambiente geopolítico, e a partir de uma perspectiva tomada das teorias críticas. Tal campo, muitas vezes designado como "economia política da informação" (bem como estudos voltados para as ligações entre "informação, cidadania e democracia") começou a problematizar a desigual produção e acesso a fontes, serviços e sistemas de informação por parte dos diferentes países do mundo e, dentro destes países, por parte de diferentes grupos ou classes sociais. De uma preocupação com o acesso físico à informação, tais estudos evoluíram para a compreensão das competências e capacitações envolvidas com a produção e o uso da informação. Mais recentemente, passaram a destacar como os contextos econômicos, políticos, regulatórios, sociais e culturais nos quais essas fontes, serviços e sistemas se inserem são coletivamente apropriados e usados para sustentar ou combater relações estruturais de poder, bem como para embasar os "livros verdes" da "sociedade da informação” promovidos por diferentes países.

Uma quarta subárea que se desenvolveu é a relacionada com os estudos sobre representação da informação. Num primeiro momento tais estudos se desenvolveram estritamente vinculados à pesquisa em recuperação da informação, com a comparação dos indicadores de precisão e revocação de diferentes linguagens e instrumentos de representação dos conteúdos dos documentos. Depois, foram considerados os aspectos relacionados com a dimensão cognitiva dos usuários, combinando descobertas sobre necessidades de informação e estratégias de busca da informação (fenômenos/atributos que não estão presentes na fisicalidade dos documentos) para a construção de sistemas de recuperação da informação. Em anos mais recentes, as possibilidades trazidas com o hipertexto e as interfaces digitais proporcionaram um grande avanço na própria percepção do caráter essencialmente construído dos processos de representação. Organizar e representar a informação não são processos de "reprodução" da realidade, não consistem na produção de um "espelho" do real - antes, significam diferentes maneiras (realizadas por atores específicos, em contextos sócio-históricos específicos e, importante destacar, a partir de tecnologias específicas) por meio das quais a realidade é apreendida e sistematizada. Vêm aumentando de importância estudos em representação da informação em "domínios" específicos (noção construída a partir da ideia de "comunidade de discurso" de Wittgenstein) e construção de sistemas de representação singulares - como por exemplo as folksonomias, as ontologias e as diversas formas de indexação social.

Outra subárea são os estudos de usuários da informação. Inicialmente, tal subárea constituiu-se de estudos buscando padrões de uso da informação, por meio da medição do acesso físico a determinados documentos ou sistemas de informação e sua correlação com fatores sociodemográficos dos usuários. Nos anos seguintes, foi se desenvolvendo a área conhecida como "comportamento informacional", dedicada aos diversos modelos por meio dos quais se compreendia a totalidade do comportamento humano em relação à informação, desde a percepção da necessidade, passando pelo engajamento em ações de busca, chegando às variadas formas de uso e apropriação da informação. Em anos mais recentes, nesta subárea têm se manifestado os estudos sobre "práticas informacionais", voltados para o estudo da ligação entre aspectos informacionais socioculturais (formas coletivas de se relacionar com a informação, critérios coletivos de relevância, necessidade, etc) e os comportamentos informacionais individuais.

Também na subárea de estudos métricos houve uma gradual evolução. Inicialmente tais estudos se desenvolveram na esteira da Bibliometria, voltados 
para o estabelecimento e a confirmação de leis sobre produtividade de autores, distribuição de periódicos em listas de citações, entre outras. Nos anos seguintes, com a Cientometria e a Informetria, buscou-se aprimorar estes estudos questionando-se, por exemplo, as razões pelas quais documentos são citados em outros. Em anos mais recentes, estudos vêm sendo desenvolvidos relacionando resultados informétricos com dimensões geopolíticas ou redes e comunidades de pesquisa e suas relações estruturais, bem como a construção de mapas de visualização de literaturas.

No desenvolvimento e nas pesquisas realizadas no âmbito de cada uma destas subáreas, deu-se uma progressiva sofisticação do conceito de informação, expressa sobretudo em dois momentos paradigmáticos para o campo.

O primeiro deles consiste num conjunto de reivindicações teóricas elaboradas desde a década de 1960 em torno da necessidade de se incorporar o conceito de "conhecimento" na definição de "informação". No evento The Copenhagen Conference Theory and Application of Information Research, ocorrido em 1977, na Dinamarca, estabeleceu-se um consenso sobre essa questão. Nos anos seguintes, tornou-se hegemônica uma definição tríade de informação: de um lado há os "dados", isto é, aquilo que tem existência material, os documentos, os registros de conhecimento; de outro lado há o "conhecimento", aquilo que está "dentro da mente" das pessoas; entre ambos, como resultado de sua interação, está a "informação". Ou seja, a informação é a medida da alteração que os dados provocam numa estrutura de conhecimento. Algo não é mais compreendido como informativo em si. Os dados, aquilo que tem existência material, possuem uma dimensão objetiva (e ela define um certo horizonte de possibilidades de significado). Já o conhecimento do sujeito também estabelece um horizonte de compreensão, por ser composto de coisas "já sabidas" e por quadros de sentido nos quais o já sabido se acomoda.A informação emerge do encontro essas duas esferas, aquilo que o dado "diz" e aquilo que o conhecimento "permite" compreender do dado. Tem-se aqui um quadro de compreensão da informação mais complexo. O símbolo maior dessa inovação teórica foi a fórmula de Brookes, que define informação como o estado de conhecimento do indivíduo alterado pela incorporação de uma variação de informação, e sua fundamentação se deu com os trabalhos de Nicholas Belkin no começo dos anos 1980 em torno da teoria dos Anomalous States of Knowledge. Nos anos seguintes, diversos autores, como Tom Wilson, Carol Kuhlthau, Brenda Dervin, Perti Vakkari, Peter Ingwersen e David Ellis, engajaram-se em pesquisas tendo como fundamento esta noção de informação.

Mas as subáreas da Ciência da Informação continuaram promovendo avanços teóricos e conceituais. Novas questões continuaram a ser formuladas indicando a necessidade de superação do modelo cognitivo consolidado até então. Em 1991, a comunidade científica da $\mathrm{Cl}$ promoveu em grande encontro internacional, o I CoLIS - International Conference on Conceptions of Library and Information Science, realizado em Tampere, na Finlândia. Diversos artigos foram apresentados na ocasião, representantes das mais diversas subáreas $\mathrm{da} \mathrm{Cl}$, apresentando resultados de pesquisas e reflexões que apontavam que esse "algo" identificado como "informação", obtido no processo de interação entre dados e conhecimento, não era definido apenas pelo sujeito específico, um sujeito individual, isolado, destacado do mundo e do convívio com outros. Antes, os contextos específicos (as realidades históricas, políticas, econômicas, culturais) são parcialmente determinantes do processo. Ao mesmo tempo, o coletivo, isto é, as demais pessoas com quem o sujeito específico interage, também são fundamentais na determinação 
do processo - ninguém conhece sozinho, necessidades e usos de informação são coletivamente formados. O próprio conceito de "conhecimento" foi reformulado, não sendo mais compreendido com simples adição de dados a um estado mental, mas sim dentro de um quadro mais complexo relacionado com diferentes processos de assimilação, acomodação, interpretação, imaginação, análise e síntese. Ou seja, as pesquisas desenvolvidas nas últimas duas décadas evidenciaram o caráter essencialmente contextual e intersubjetivo dos fenômenos informacionais (FROHMANN, 2008; HJORLAND;ALBRECHTSEN, I 995; RENDÓN ROJAS, 2005).

Essa evolução do conceito de informação foi mapeada por diferentes autores, de diferentes contextos. Saracevic (1999) apontou a existência de três conceitos de informação: um sentido restrito (sinais enviados por um emissor a um receptor), um sentido amplo (informação envolve processamento cognitivo e compreensão) e um sentido ainda mais amplo (informação existe em um contexto e no decurso de uma tarefa). Ørom (2000) identificou, na $\mathrm{Cl}$, a existência de um modelo físico num primeiro momento, superado por um modelo cognitivo. Para este autor, no momento contemporâneo estariam se desenhando abordagens alternativas a partir da aproximação com a comunicação e a semiótica, privilegiando a dimensão cultural da informação. Numa linha bastante próxima, Fernández Molina e Moya-Anegón (2002) identificaram três grandes modelos de estudo na $\mathrm{Cl}$ : o modelo positivista (abordagem física da informação), o cognitivo (mentalista) e o sociológico (contextualiza, privilegia as relações que uma coletividade estabelece com os conhecimentos registrados que ela mesma cria).

Os esquemas acima podem ser bem representados pela sistematização que Capurro (2003) realizou quando proferiu a conferência magna do Enancib, o Encontro Nacional de Pesquisa em Ciência da Informação, em 2003. Na ocasião, o autor definiu a evolução da Ciência da Informação como sendo a história da consolidação de um primeiro paradigma, o físico (que privilegia a idéia de informação como "coisa" a ser transferida de um ponto a outro); que foi questionado por um outro, o cognitivo (inspirado na filosofia de Popper e que enfatiza a informação como elemento alterador dos modelos mentais dos usuários); que, por fim, vem sendo também questionado por um terceiro, denominado social ou pragmático (que busca entender o que é informação por parte de comunidades de usuários e de sua inserção em contextos socioculturais específicos, resgatando a idéia de informação como construção intersubjetiva). Desde então, diferentes autores têm buscado consolidar estudos fundamentados nesta perspectiva de estudos da informação (CAPURRO, 2009; CRONIN, 2008; GARCÍA GUTIÉRREZ, 2008; SILVA, 2006).

Tem-se, assim, um progressivo incremento de dimensões e problemas incorporados como objeto de estudo para o campo da Ciência da Informação. De certa forma, o movimento foi bastante semelhante ao que aconteceu com a Museologia - da concretude à abstração, da simplificação à complexidade.Assim, as perspectivas contemporâneas de estudo da informação mostram-se portanto muito pertinentes para aplicação e compreensão dos fenômenos museológicos.

\section{O espaço do diálogo}

O quadro epistemológico contemporâneo da Museologia tem um importante significado na própria configuração do campo como disciplina científica. Esse quadro pode ser sintetizado pela discussão promovida por Stránský (2008), que em 1980 colocava o problema da identidade científica da Museologia. Em sua visão, a área se desenvolveu, desde o século XIX, de maneira bastante empí- 
rica e intuitiva, tratando de questões organizacionais e técnicas, contemplando a historiografia dos museus e descrições de práticas individuais, pouco voltadas para o descobrir. Mas, em sua avaliação, gradualmente a Museologia foi se aproximando de um estatuto científico, por meio da qual se afastou da prática para, em seguida, relacionar-se novamente com ela - porém, numa nova condição.

Conforme a discussão empreendida neste texto, de 1980 para cá muito se avançou no campo em direção à sua consolidação, não apenas no sentido das teorias e práticas formuladas desde o início do século XX (agrupadas, neste texto, em quatro eixos) como, e principalmente, pelos arranjos e reconfigurações realizadas a partir delas nas últimas três décadas - as abordagens contemporâneas em torno da Nova Museologia, da mediação, do patrimônio imaterial, dos museus virtuais e, enfim, da ampliação do objeto da área do museu (sua organização, suas técnicas e seus acervos) para a musealidade.

Como apontou Stránský (apud DELOCHE, 2002, p. 108), da mesma forma que o objeto da Ciência Política não são as instituições políticas mas "o político", isto é, a dimensão política de toda ação humana, assim também o objeto da Museologia não é o museu, a instituição, mas sim “o museal”, uma dimensão da ação humana presente nos mais diversos contextos - inclusive, mas não só, no museu.

Um paralelo com essa discussão, na Ciência da Informação, é a discussão sobre o conceito de informação promovida por Capurro (2009). O autor retorna à própria origem do termo, os conceitos gregos de eidos (ideia) e morphé (forma), para recompor o significado de informação como "dar forma a algo". Informação, portanto, se inscreve no âmbito da ação humana sobre o mundo ("in-formar"), apreendendo-o por meio do simbólico, nomeando e classificando os objetos que conhece (objetos da natureza), criando objetos que passa a utilizar (com as mais diversas finalidades), produzindo registros que constituem novos objetos (textos impressos, visuais, sonoros) e criando ainda registros destes registros (catálogos, índices, inventários, etc).

Informação, nesse perspectiva (que é aquela presente nas abordagens contemporâneas da $\mathrm{Cl}$ ), é um conceito que perpassa todo esse processo. Tem origem na produção de registros materiais e se prolonga nas atividades humanas (incluindo aí as museológicas) sobre esses registros. Mas é ainda mais ampla do que isso: é tudo aquilo que envolve essa ação humana a partir do primeiro registro, do primeiro ato de "in-formar". Parte da ação humana comum, cotidiana, de apreender o mundo e produzir registros materiais desse processo; chega às instituições e procedimentos técnicos criados especificamente para intervir junto a estes registros; e os ultrapassa nos mais diversos usos, fluxos, apropriações, contextos. Dada sua amplitude, surge com grande potencial de permitir o estudo (a partir de uma perspectiva informacional) dos processos museológicos, vindo ao encontro das perspectivas contemporâneas da Museologia que a vêem como sendo muito mais do que os procedimentos técnicos definidos pelo modelo custodial e tecnicista inicialmente consolidado.

Naturalmente, os fenômenos museais possuem muito mais do que uma dimensão informacional. Eles também possuem uma dimensão comunicativa, administrativa, educacional, histórica, entre outras. Cursos de Museologia poderiam se instalar tranquilamente em faculdades ou escolas de Comunicação, de Administração, de Educação, de História, e se relacionar com essas áreas. Em cada um desses casos, contudo, o diálogo se daria numa direção específica. Nesse sentido, o fato concreto é que, em alguns contextos, como mencionado no início deste texto, a Museologia ocupa o espaço institucional da Ciência da Informação. Pode-se pensar que isso seja ou venha a ser um mero acaso, ou 
pode se pensar nisso como uma ótima oportunidade de promoção de estudos e pesquisas a partir da dimensão informacional envolvida nas práticas museológicas, ao mesmo tempo em que tal oportunidade também possibilita o diálogo com os campos da Arquivologia e da Biblioteconomia. Em suma, uma oportunidade de incremento teórico e conceitual tanto para a Museologia como para a Ciência da Informação, a somar-se aos avanços já realizados nas décadas que se seguiram ao surgimento das duas áreas.

\section{Referências}

ALONSO FERNÁNDEZ, Luis. Introducción a la nueva museología. Madrid: Alianza, 1999.

ANDERSON, Benedict. Comunidades imaginadas: reflexões sobre a origem e a difusão do nacionalismo. São Paulo: Companhia das Letras, 2008.

BENNETT, Tony. Pasts beyond memory: evolution, museums, colonialism. Londres: Routledge, 2004.

BOLAÑOS, María. La memoria del mundo: cien años de museología. Gijón:Trea, 2002.

BOURDIEU, Pierre.A distinção: crítica social do julgamento. São Paulo: Edusp, 2007.

CAMERON, Duncan. The museum as a communication system and implication of museum education. Curator, American Museum of Natural History, v. I I, n. I, p. 33-40, 1968.

CAPURRO, Rafael. Epistemologia e ciência da informação. In: ENCONTRO NACIONAL DE PESQUISA EM CIÊNCIA DA INFORMAÇÃO, 5., 2003, Belo Horizonte.Anais... Belo Horizonte:Associação Nacional de Pesquisa e Pós-Graduação em Ciência da Informação, 2003.

CAPURRO, Rafael. Pasado, presente y futuro de la noción de información. In: ENCUENTRO INTERNACIONAL DE EXPERTOS EM TEORÍAS DE LA INFORMACIÓN, I., 2009.Anais... Leon: Universidad de Leon, 2008.

CRONIN, Blaise. The sociological turn in information science. Journal of Information Science, v. 34, n. 4, p. 465-475, 2008.

DAVIS, Peter. Ecomuseums: a sense of place. Londres: Leicester University Press, 1999.

DAY, Ronald. The modern invention of information: discourse, history and power. Carbondale: Southern Illinois University Press, $200 \mathrm{I}$.

DELOCHE, Bernard. El museo virtual. Gijón:TREA, 2002.

DUARTE,Adelaide Manuela da Costa. O Museu Nacional da Ciência e da Técnica: 197| - 1976. Coimbra: Ed. Universidade de Coimbra, 2007.

FEATHER, J.; STURGES, P. International encyclopedia of information and library science. Londres: Routledge, 2003.

FERNÁNDEZ DE PAZ, Esther;AGUDO TORRICO, Juan. (Org.). Patrimonio cultural y museología: significados y contenidos. Santiago de Compostela: Federación de Asociaciones de Antropología del Estado Español (FAAEE), 1999.

FERNÁNDEZ MOLINA, Juan Carlos; MOYA-ANEGÓN, Félix. Perspectivas epistemológicas "humanas" en la documentación. Revista Española de Documentación Científica, v. 25, n. 3, p. 24I-253, 2002.

FROHMANN, Bernd. O caráter social, material e público da informação. In: FUJITA, Mariângela; MARTELETO, Regina; LARA, Marilda (Org.).A dimensão epistemológica da ciência da informação. São Paulo: Cultura Acadêmica, 2008. p. 19-34. 
GARCÍA GUTIÉRREZ,António. Outra memória é possível: estratégias descolonizadoras do arquivo mundial. Petrópolis:Vozes, 2008.

GÓMEZ MARTÍNEZ, Javier. Dos museologías: las tradiciones anglosajona y mediterránea: diferencias y contactos. Gijón:Trea, 2006.

HIGGINS, Tony; MAIN, Peter; LANG, Janet (Ed.). Imaging the past: electronic imaging and computer graphics in museums and archaeology. Londres:The British Museum, 1996.

HJORLAND, Birger;ALBRECHTSEN, Hanne. Toward a new horizon in information science: domain analysis. Journal of the American Society for Information Science, v. 46, n. 6, p. 400-425, 1995.

HOOPER-GREENHILL, Eilean. Los museos y sus visitantes. Gijón:Trea, 1998.

LEAL, João. O patrimônio imaterial e a antropologia portuguesa:uma perspectiva histórica. In: COSTA, P. (Org.). Museus e património imaterial: agentes, fronteiras, identidades. Lisboa: Instituto dos Museus e da Conservação, 2009. p. 289-295.

MAGALHÃES, Fernando. Museus: património e identidade: ritualidade, educação, conservação, pesquisa, exploração. Porto: Profedições, 2005.

MAIRESSE, François; DESVALLÉS, André. Brève histoire de la muséologie: des Inscriptions au Museé virtuel. In: MARIAUX, Pierre (Org). L'object de la muséologie. Neuchâtel: Institut de l'Art et de Muséologie, 2005.

MARÍN TORRES, María Teresa. Historia de la documentación museológica: la gestión de la memoria artística. Gijón:TREA, 2002.

MARTY, Paul; JONES, Katherine. (Org.). Museum informatics: people, information and technology in museums. Nova lorque: Routledge, 2008.

MENDES, José Amado. Estudos do patrimônio: museus e educação. Coimbra: Univ. Coimbra, 2009.

$\varnothing R O M$, Anders. Information science, historical changes and social aspects: a Nordic outlook. Journal of Documentation, v. 56, n. I, p. I2-26, 2000.

PEARCE, Susan (Ed.). Museums and the appropriation of culture. Londres: Athlone, 1994.

PÉREZ SANTOS, Eloísa. Estudio de visitantes en museos: metodología y aplicaciones. Gijón:Trea, 2000.

POULOT, Dominique. Museé et muséologie. Paris: La Découverte, 2002.

RENDÓN ROJAS, Miguel Ángel. Relación entre los conceptos: información, conocimiento y valor: semejanzas y diferencias. Ciência da Informação, v. 34, n. 2, p. 52-6I, maio/ago. 2005.

SANTACANA MESTRE, Joan; HERNÁNDEZ CARDONA, Francesc Xavier. Museologia crítica. Gijón:Trea, 2006.

SARACEVIC, Tefko. Information science. Journal of the American Society for Information Science, v. 50, n. 12, p. I05I-I063, 1999.

SHERA, J.; CLEVELAND, D. History and foundations of information science. Journal of the American Society of Information Science and Technology, v. I2, p. 249-275, 1977.

SILVA,Armando Malheiro.A informação: da compreensão do fenômeno e construção do objecto científico. Porto:Afrontamento, 2006.

STRÁNSKÝ, Zbynek. Sobre o tema “Museologia: ciência ou trabalho prático?”. Museologia e Patrimônio, v. I, n. I, p. I0I-I05, jul./dez., 2008. 
VAN MENSCH, Peter. Magpies on Mount Helicon. In: SCHÄRER, Martin (Org.). Museum and community. ICOFOM Study Series, v. 25, p. I 33-I 38, 1995.

VEGA-ALMEIDA, Rosa; FERNÁNDEZ MOLINA, Juan Carlos; LINARES, Radamés. Coordenadas paradigmáticas, históricas y epistemológicas de la Ciencia de la Información: una sistematización. Information Research, v. I4, n. 2, 2009.

WOODHEAD, Peter; STANSFIELD, Geoffrey. Keyguide to information sources in museum studies. Londres: Mansell, 1994.

ZELLER, Terry. The historical and philosophical foundations of art museum education in América. In:BERRY, Nancy; MAYER, Susan (Org.). Museum education: history, theory and practice. Reston: National Art Education Association, 1989. p. 10-89.

ZORICH, Diane.A survey on digital cultural heritage initiatives and their sustainability concerns. In: PARRY, Ross (Ed.). Museums in a digital age. Oxon: Routledge, 2010 . p. 406-4I6.

Artigo recebido em maio de 2013 . 